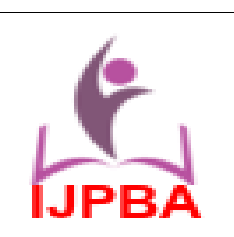

\title{
HOW TO WRITE A RESEARCH ABSTRACT
}

\author{
Dr. Indrajeet P Shah \\ MD (Homo), [PhD. (Scholar)] \\ Department of Medicine, MNR HMC \& H \\ Sangareddy, Hyderabad
}

\begin{abstract}
An abstract is like a movie trailer. People will only consider reading the rest of the manuscript if they find your abstract interesting. It is an outline/brief summary of your paper and your whole project.
\end{abstract}

Keywords: Abstract, research, descriptive and informative research.

\section{INTRODUCTION}

Abstract is most important text that introduces the research regarding your thesis. It is the gist of your study and functions to provide an overview of your work. It should clearly reflect the purpose and content of the research that you have done. An abstract is a summary of completed research project or thesis. A well written abstract will make the reader to read more about the research paper. It should not include any information that is not subsequently appear in your research. In addition, it should not leave out important details that are significant for research and we should not comment but we must report.

\section{What is an Abstract}

It is like a trailer of research or defining its entire research or thesis in few lines. It is strongly advised that before writing an abstract first draw the outline and draft. And it should be written at the end of completing the research or thesis. It is a gist of the entire research paper or thesis. It is not to write a small essay or a small passage, it is an original work. It is a well-written paragraph of approximately 250 words. The function of the abstract is to outline brief all parts of the paper. It should be written at the beginning of your paper, immediately after the title of the research paper ${ }^{1}$. Although the abstract should be written at the end of the research project, once you are sure of the conclusion you will reach. An abstract is useful for a researcher, for the different academic community to share the process or to share the information. ${ }^{3}$

\section{Reasons for writing abstracts?}

Abstracts are usually required for:

- For submission of articles to journals

- For application for research grants

- For completion and submission of theses

- For submission of proposals for conference papers. ${ }^{6}$

\section{Good Qualities of abstract}

\section{A. Edit carefully}

Abstract is an important part of research paper or thesis, Reread your research paper with the purpose of summarizing in mind. Revise your rough draft to correct weaknesses in organization and coherence, cut unnecessary information and add important information 
originally left out. It should fit within word limit.

\section{B. WRITING THE PARTS OF AN ABSTRACTSTEP- BY-STEP PROCESS:}

1. Write 1-2 introduction sentences that explain topic, purpose, and research question(s).

2. Write 1-2 sentences should define your research methodology (this may also include the type of data analysis you used).

3. Write 1-2 sentences about the result or findings.

4. Write 1-2 sentences containing your conclusions and recommendations.

5. Active voice is preferable to passive voice "We studied 30 patients with Haemorroids." is

Much better than "Thirty patients with Haemorroids were studied."

6. Eliminate unnecessary words

7. Ensure that verb tenses are consistent and correct

8. Do not write abbreviations without defining it first. $^{2}$

\section{Why abstracts are not accepted?}

Most common deficiencies encountered:

- Poor presentation

- Weak discussion

- Lack of originality

- Poor methods

- Inappropriate statistical analysis

- Inadequate results. ${ }^{4}$

Types of abstract:

\section{Descriptive abstracts}

It is an abstract describe the major points of the project to the reader. These abstracts are inconvenient in that, by not including a detailed presentation of the method, results and conclusions. Ultimately, these guide readers on the nature of the contents of the article, but it is necessary to read the whole manuscript to know further details. This type of abstract is usually very short (50-100 words). Most descriptive abstracts have certain key parts in common. ${ }^{7}$ they are:

- background

- purpose

- Interest/focus of paper

\section{Informative abstracts}

An informative abstract informs all essential points of the project to the reader. Informative abstracts are generally used for science, engineering or psychology reports. Here we must write result. This type of abstract is usually about 200 words. Mostinformative abstracts also have key parts in common. Each of these parts might consist of 1-2 sentences. The parts include:

- background

- aim or purpose of research

- $\quad$ method used

- findings/results

- Conclusion. ${ }^{5}$

\section{Conclusion}

A good abstract usually ensures a good article, writing an efficient abstract is hard work. Scientific abstracts are a challenge to write and for the success of our publications, careful and planned writing of the abstract is essential.

Acknowledgments: I sincerely acknowledge our management and the Principal MNR HMC and $\mathrm{H}$, Sangareddy for their support for their support for this work.

Financial support: Nil 
Conflicts of Interest: The authors declare no conflict of interest.

\section{References:}

1. Sandeep B Bavdekar1, Nithya J Gogtay2, Writing an Abstract for a Research Manuscript: Providing an Honest, Succinct and Complete Summary, Journal of The Association of Physicians of India, Vol. 63, December 2015.

2. Susan E. Shapiro, Nancy Donaldson RN, How to Write a Good Abstract: Dos, Don'ts, and Helpful Hints, UCSF Stanford Centre for Research \& Innovation in Patient Care.

3. Andrei V. Alexandrov, Michael G. Hennerici, Writing Good Abstracts, Cerebrovasc Dis 2007;23:256-259.

4. Philip Koopman, How to Write an Abstract, http: //www.ece.cmu.edu / koopman/ essays/abstract.html
5. Mala Babagana Gutti, how to write an abstract: the concise approach,Jan 2019, https://www.researchgate.net/ publication/330523135

6. Nakayama T, Hirai N, Yamazaki, Naito $\mathrm{M}$ : Adoption of structured abstracts by general medical journals and format for a structured abstract. J Med Libr Assoc 2005; 93: 237-242.

7. James Hartley and Guillaume Cabanac, short notes, Thirteen Ways to Write an Abstract, Publications 2017, 5, 11; doi:10.3390/publications5020011, www.mdpi.com/journal/publications. 